\title{
مدى هراعاة كتاب اللغة العربية للصف الأول الأساسي في الأردن لمتطلبات التعليم الصوتي
}

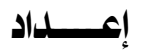

د. يوسف عثمات جبريلـ مناصرة

جامعة عمان العريية للدراسات العليا

مجلة بحوث التربية النوعية - جامعة المنصورة

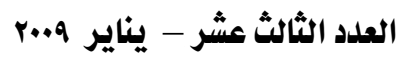


حملدى مراعاة كتاب اللغة العربية للصف الأول الأساسي فِ الأردن لمتطلبات التعليم الصوتىي 


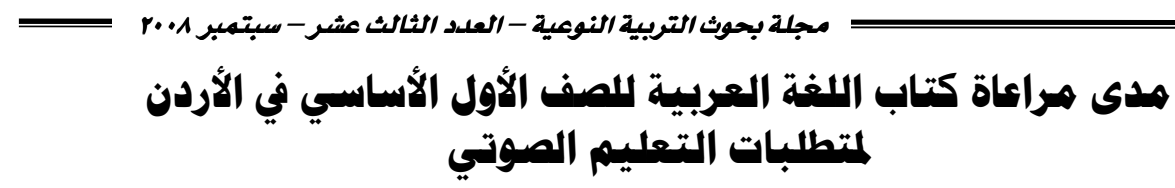

\title{
د . يوسف عثمازجبرلمناصرة
}

\begin{abstract}
axil|

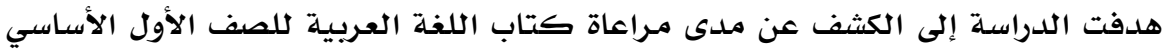

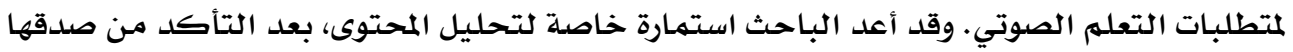

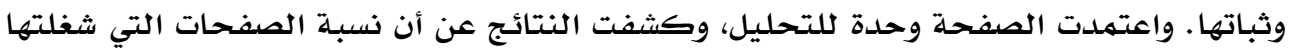

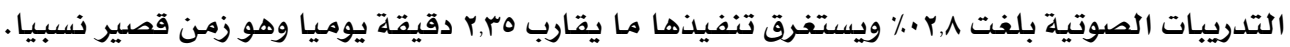

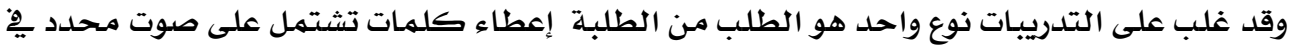

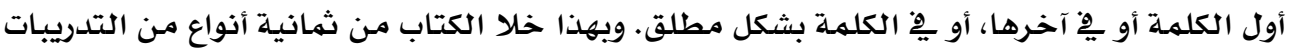

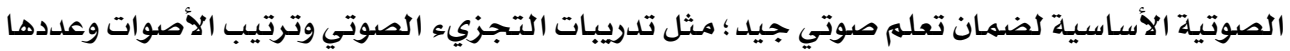

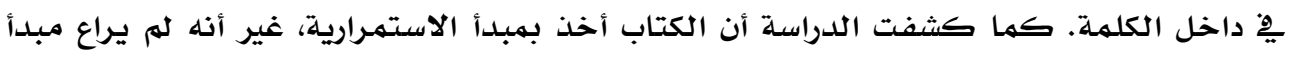

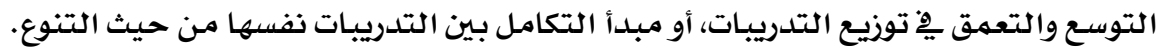

\section{ABSTRACT}

The study aimed at discovering to what extent does the Arabic Language Textbook for first grade take into consideration the requirements of phonological learning. To answer the questions of the study, the researcher designed a special tool for analyzing the textbook content, and verified its validity \& reliability. The page was considered as a unit of analysis and as an indicator for time consuming. The findings were as follow: $02.8 \%$ of the textbook pages only were occupied by Phonological exercises, which means that only 02.35 minutes will be spent a day in teaching phonological awareness. Nearly eight out of nine selected kinds of phonological exercises were neglected; such as phonemes' segmentation, number \& order of phonemes in the words articulated. In addition, it was found that the principle of continuity was available, but the textbook didn't take into consideration the principles of sequence and integration.

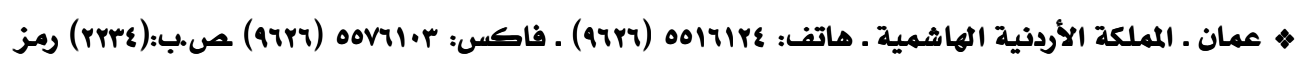

بريدي: (II90r) 


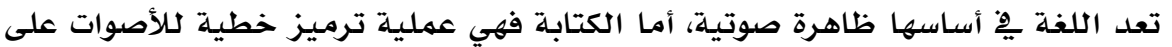

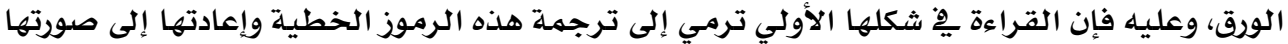

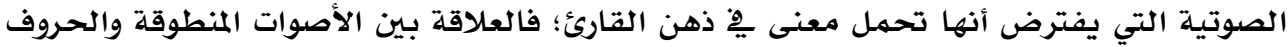

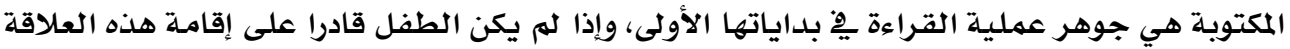

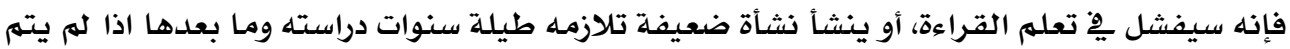

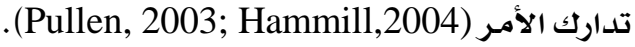

ويشكل تعلم القراءة والكتابة المحور الأساسي ِِّ برنامج التعليهم ِِّ المدرسة الابتدائية ،

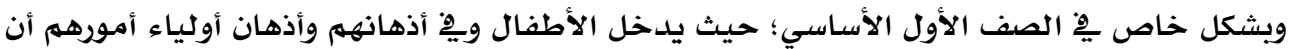

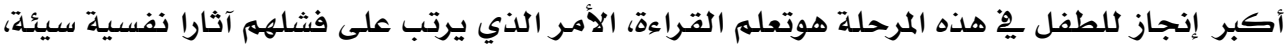

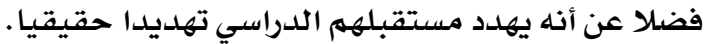

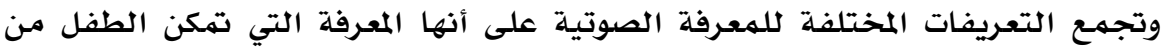

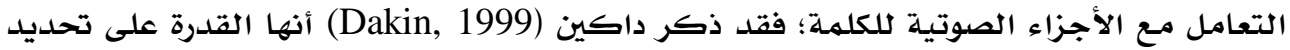

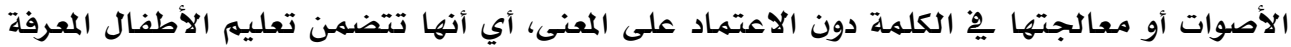

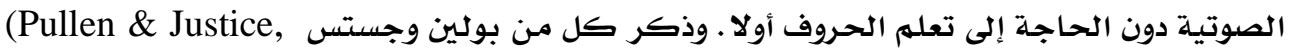

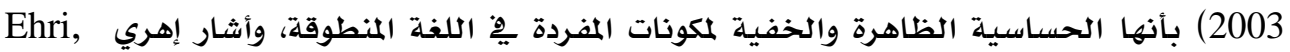

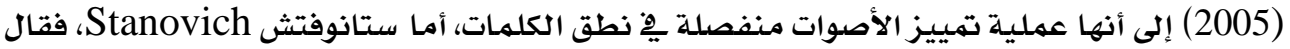

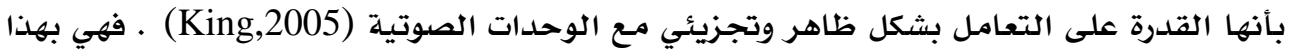

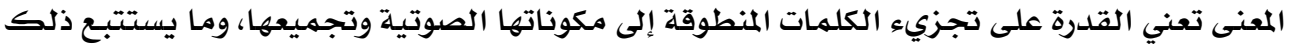

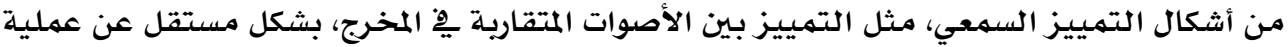

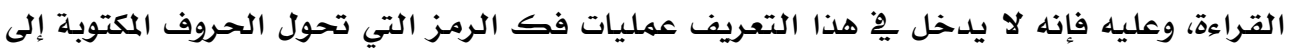

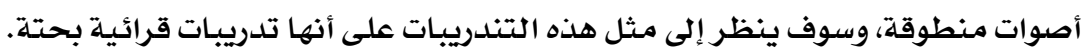

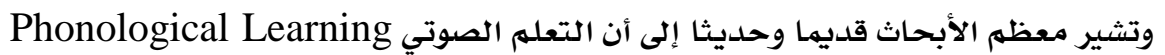

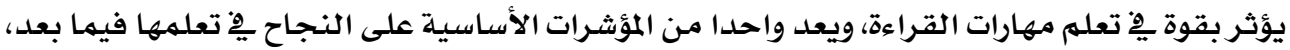

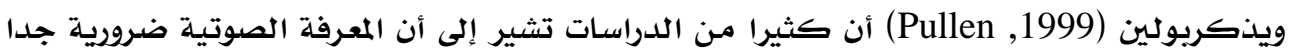

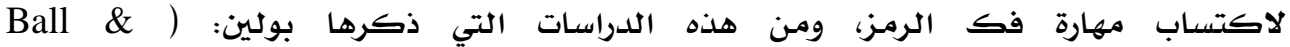
Blachman,1991;Brady, Flower \& Winbury, 1994;Byrne \& Fielding,1991; Rack, هذا

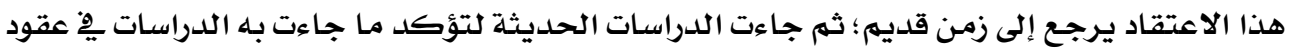

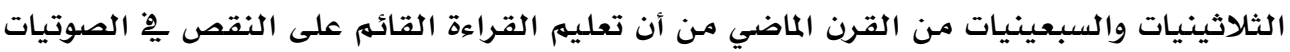

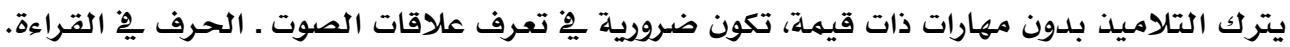

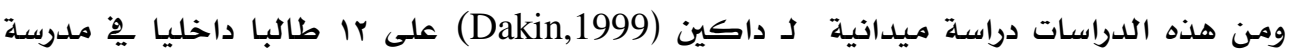




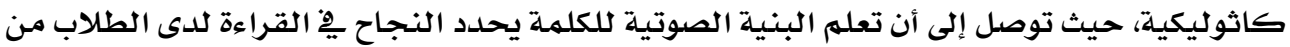

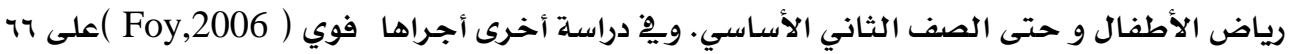

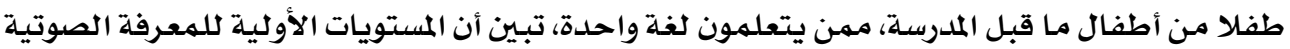

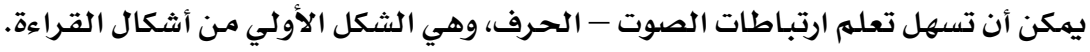

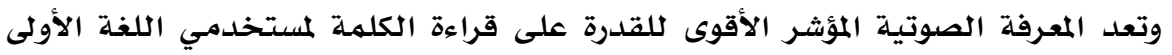

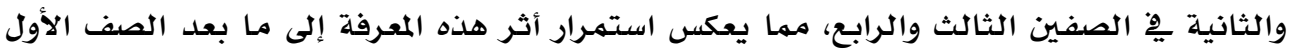

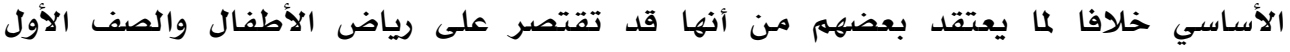

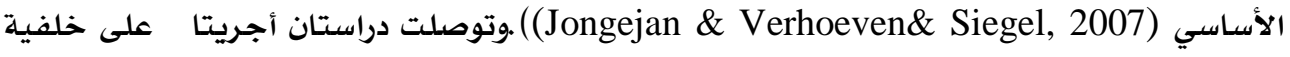

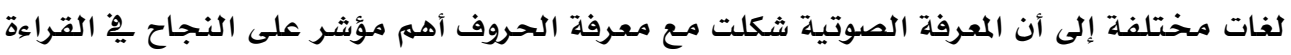

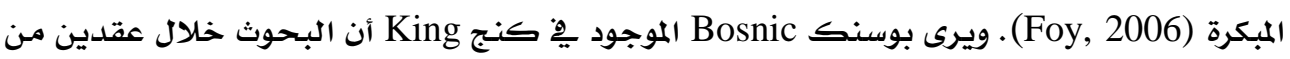

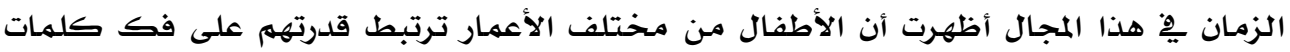

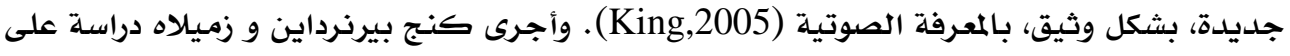

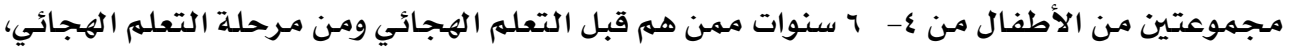

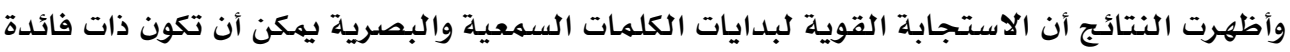

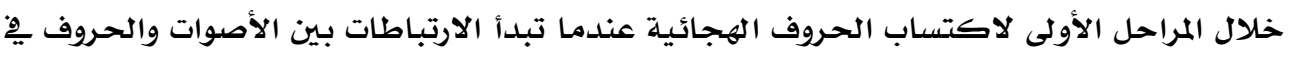

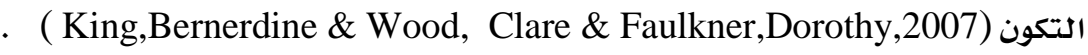

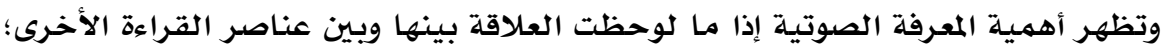

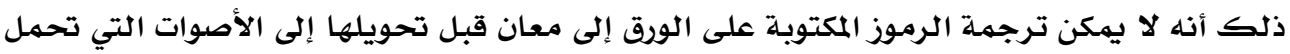

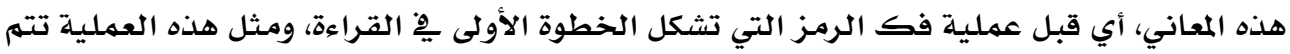

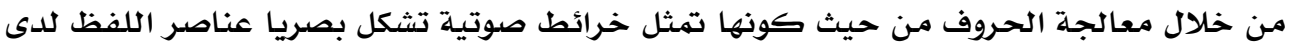

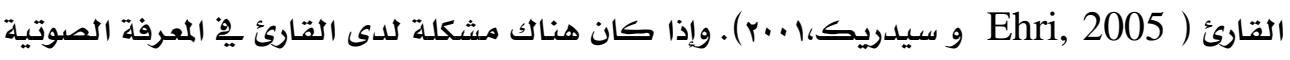

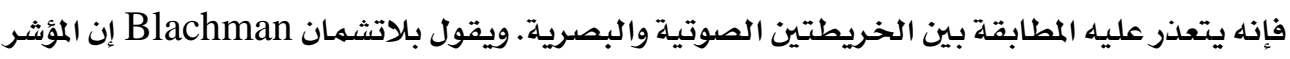
القوي لتحصيل القراءة الذي حظي على اهتمام أكبر خلال العقدين الأخيرين هو المعرفة الصوتية الهين ) .Pullen,2003 )

غير أنه يجب ألا يظن أن المعرفة الصوتية كافية وحدها لاكتساب مهارة قراءة الكلمـة، فلا

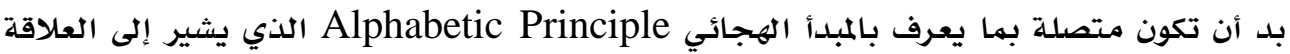

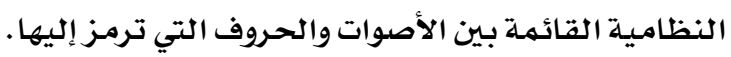

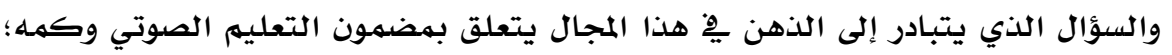

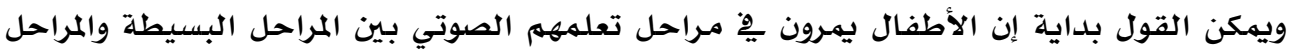

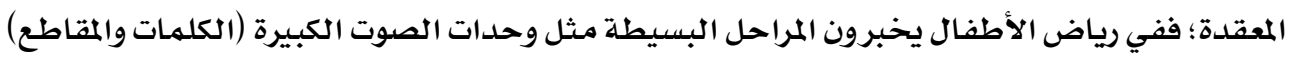

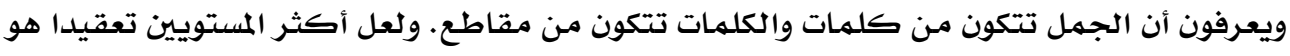

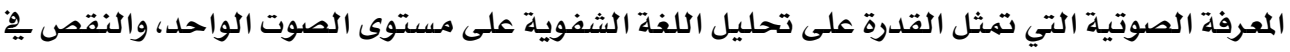


هذه المهارة يؤثر ِِّ الطلاقة ِِّ مهارات قراءة الكلمسة، ويشكل المصدر الأولي للصعوبة التي يواجهها

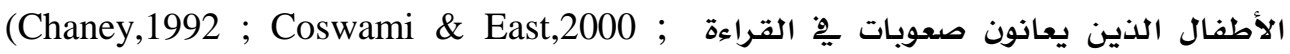

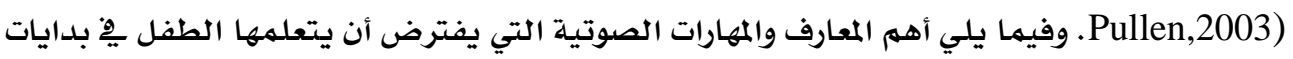

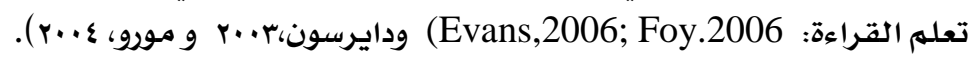

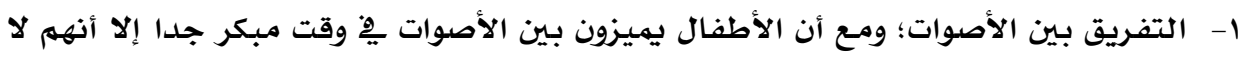

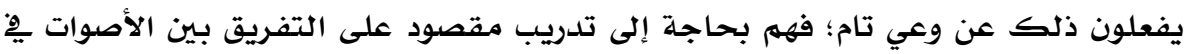

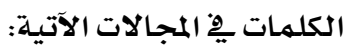
- التفريق بين الأصوات المتقاريـة ِِّ المخرج مثل السين والصاداد، والدال والضاد، والذال والظاء. - التمييز بين أصوات المد القصير والمد الطويل: بَ باء فكثير من مشكلات القراءة ناتج عن الخلط بين المد القصير والطويل.

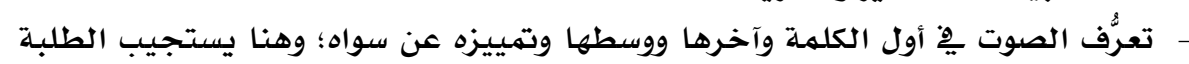

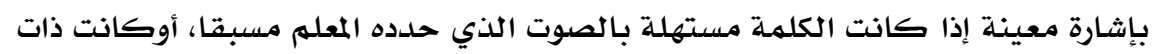

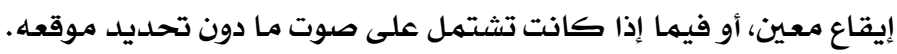

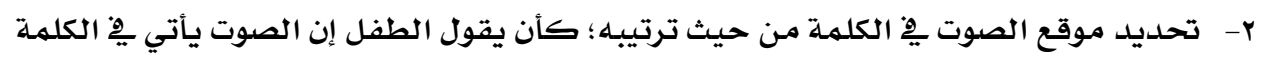

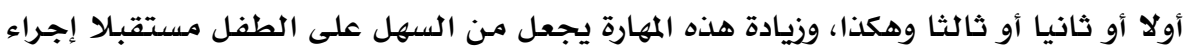

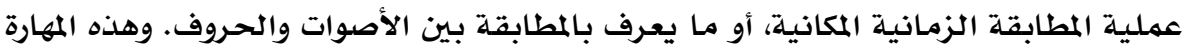

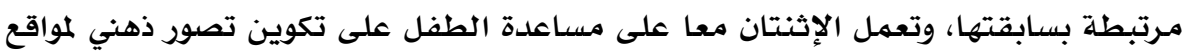

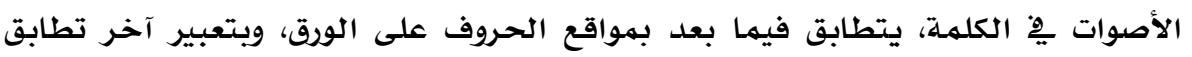
الخريطتين الصوتية والبصرية، أو الزمانية والمكانية.

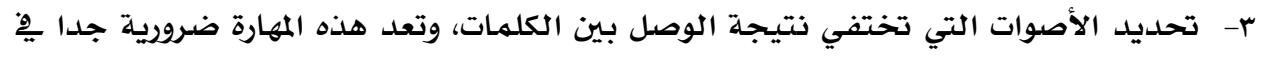

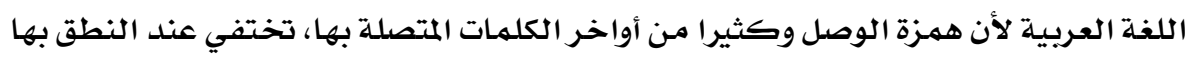

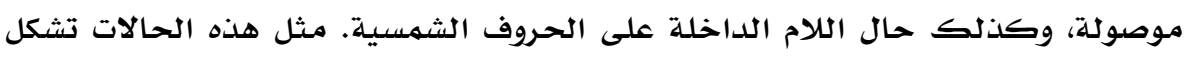

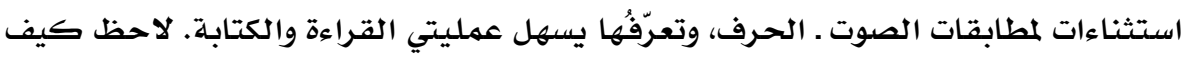

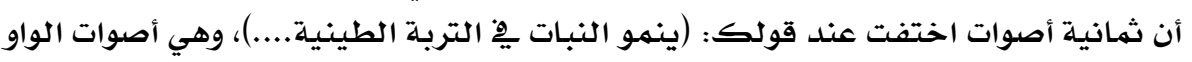

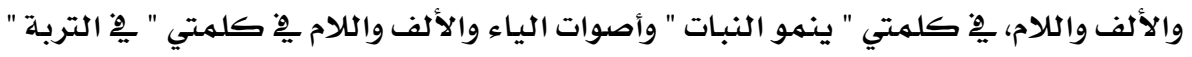

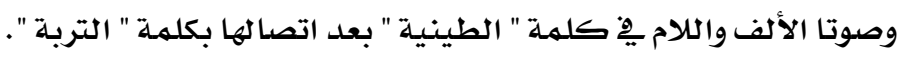

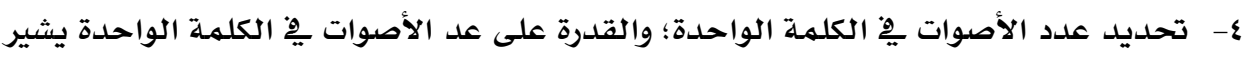

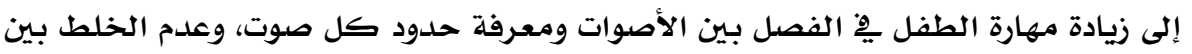
أصوات المد الطويل والقصير.

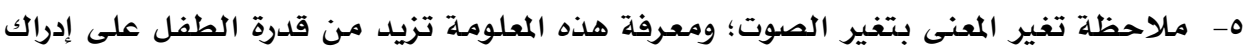

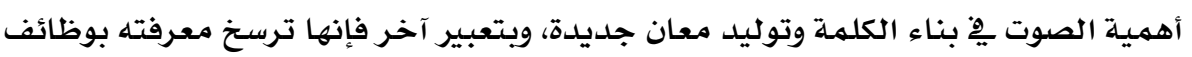
الأصوات. 
ج- حذف أصوات من الكلمـة أو إضـافتها إليها ولفظها لفظا صحيحا بعد الحذف أو الإضافة؛حيث تساعد هذه المهارة على تحليل الكلمات المكتوبـة بالفصل بين الأصول والزيادات؛ ومن ذلك زيادة لام التعريف والضهـائر المتصلة وعلامات التثنية والجمـع، وتاء التأنيث وحروف الجر

المتصلة.

V- تقطيع الكلمات صوتيا سواء أكان ذلك تقطيعا عروضيا أم صوتا صوتا، وإعادة مزج الأصوات لتشكل كلمهة كاملةة؛ ولعل هذه المهارة مـع مهارة التمييز الصوتي تشكلان لب عملية التعليهم الصوتي وفقا للتعريف الذي أجمـع عليه عدد كبير من الباحثين. ^- تدريب الذاكرة السهعية؛ ويقصد بذلك، بشكل أساسي، الذاكرة قصيرة المدى، فهي تسـاعد على استتمرار ريط الأصوات بعضها ببعض بشكل متواصل. أما فيما يتصل بكم التعليم الصوتي، فقد بينت دراسـة أجراها كنج (King,2005 ) أن

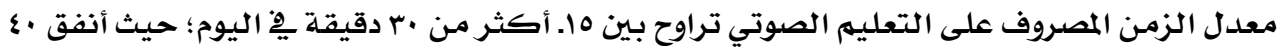

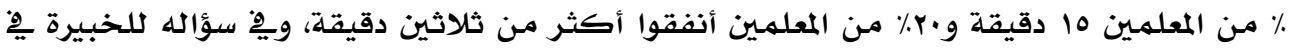
تدريس القراءة ذكرت أن معدل الزمن المنفق على التعليه الصوتي ينبغي أن يكون 10. هب دقيقة يِ

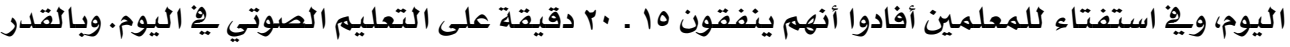
الذي تبـين فيـه هذه الدراسـة أهميـة التعليهم الصوتي فإنها تقدم فكرة عن حجهم المحتوى الخاص بالتعليم الصوتي. وغني عن القول إن مبدأ التعليم الصوتي يكاد يكون واحدا ِِِ اللغات المختلفة؛ بغض النظر عن اختلاف مدى تطابق الأصوات والحروف بين لغة وأخرى، لأن الحديث هنا عن تعليم صوتي مجررد عن قراءة الكلمـات أو تعرف الحروف.

وكها هو معروف فإن التعليهم الصوتي يبدأ يِّ معظم الأنظمهة التعليميـة التي تهتم بهذا الأمر من رياض الأطفال، ويستمـر إلى ما بعد الصف الأول الأسـاسي. وعند تحليلنـا لمهارة فك الرمـز

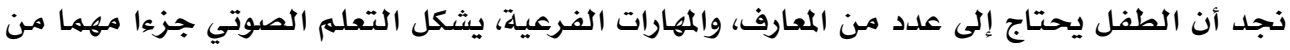
كل واحلدة منهها، ومـن ذلك: معرفة الحروف الهجائية بأصواتها وأسمائها، ومعرفة أن اللغـة المنطوقة تقابلها لغـة مكتوبـة، وأن اتجـاه الكتابـة يكون من اليهـين إلى اليسـار، ومـن أعلى الصفحة إلى أسفلها، وأن الأصوات يِّ الكلمات المنطوقة تتوالى بالطريقة نفسها التي تتوالى فيها الحروف يِّات الكلهـة المكتوبة. وريها اعتقد البعض أن هذا الجانب مـرتبط بهرحلة رياض الأطفال، وأن التعليهم يِّ الصف الأول الأسـاسي قد تجاوز موضوع التعليهم الصوتي، إلا أن دراسلة حديثة لأبي حية كشفت عن وجود نقص كبير يخ التعلهم الصوتي عند تحليلها المنهاج التفاعلي لرياض الأطفال المعد من قسهم المناهـج

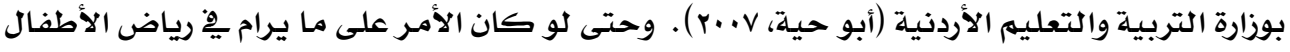
فإن نسبـة عاليـة جدا مـن الأطفال يـخلون إلى الصف الأول الأسـاسي دون المرور برياض الأطفال، كما أن الخبر اء يرون ضـرورة أن يستمـر التعليهم الصوتي من رياض الأطفال وحتى الصف الثالث الأسـاسي 


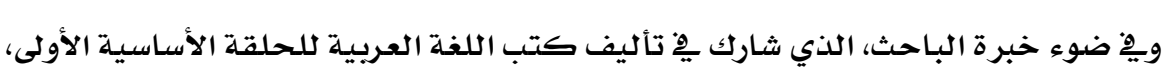

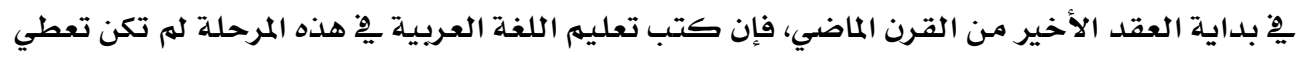

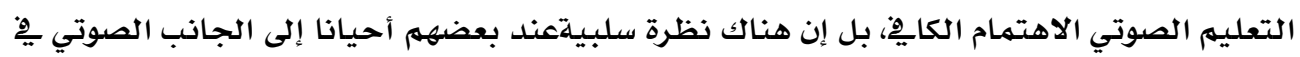

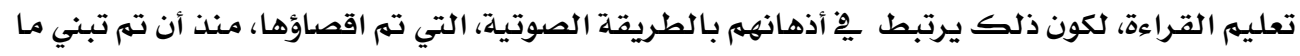

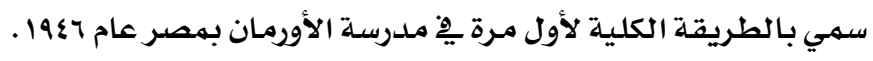

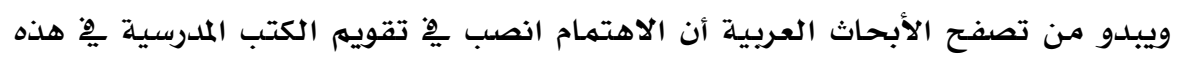

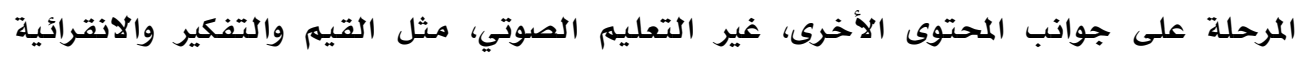

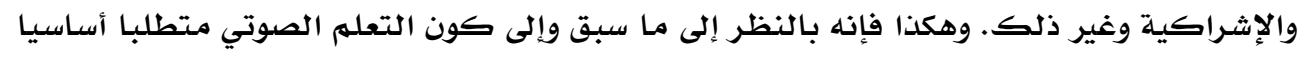

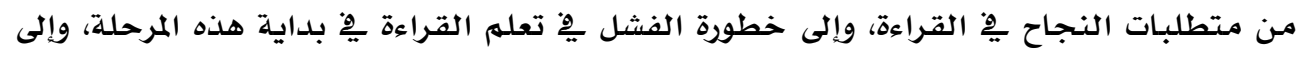

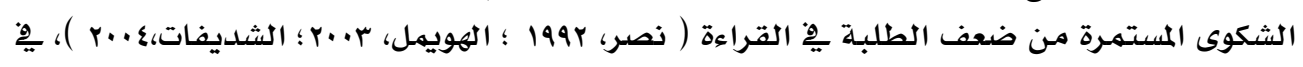

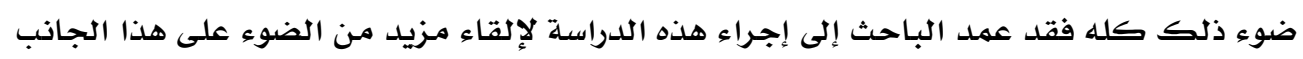

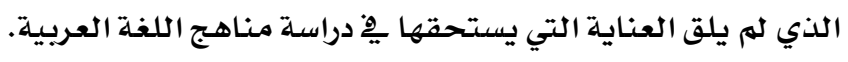

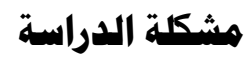

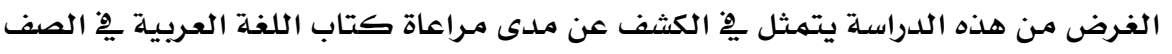

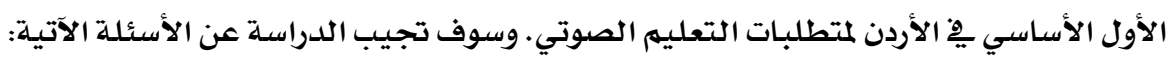

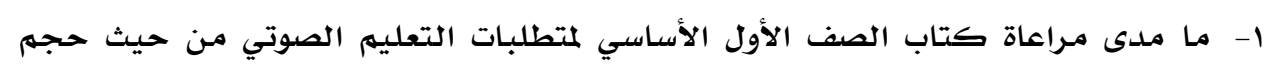

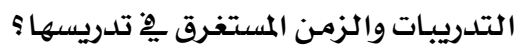

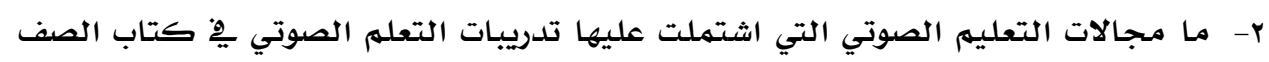

$$
\text { الأول الأساسي؟ مالات التعليع }
$$

r- ما المبادئ التنظيمية الخاصدة بتدريبات التعليم الصوتي كما تكثف عنها عملية تحليل

$$
\text { المحتوى؟ مأبادئ }
$$

\section{أهمئة الدراستة :}

تكتسب هذه الدراسة أهميتها من كونها تعالج قضية يْ غاية الأهمية ِِّ تعليم القراءة

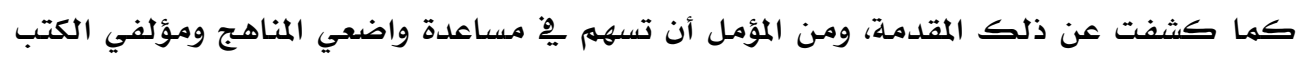

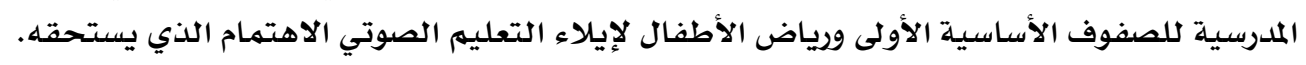

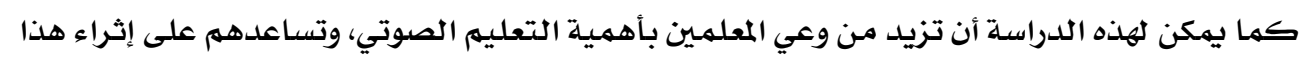

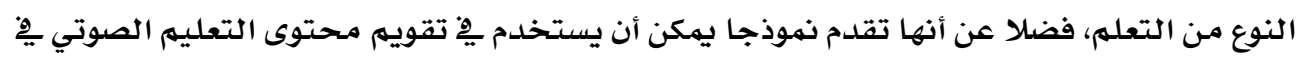

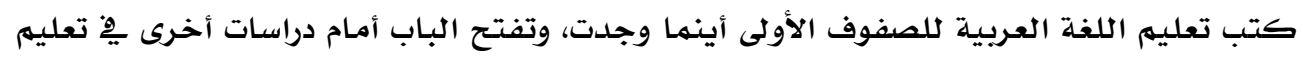
القراءة ِِِ هذه المرحلة. 


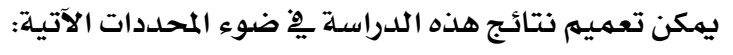

- تقتصر الدراسـة على كتاب الصف الأول الأسساسي يِ الأردن وعلى التدريبات الصوتية الخالصة فيه، إذ استثني مـن الدراسـة كل معالجـة صدتية مـرتبطة بقراءة الحروف، حيث عدت مثل هذه التدريبات نشاطات قرائية متصللة بما يسهى بالمعرفة الهجائية وليس الصوتيـة. - اقتصرت الدراسـة على استخدام استمارة خاصسة من إعداد البـاحث، لتحليل محتوى الكتاب فيما يتصل بالتدريبات الصوتيـة.

كتاب لغتنا العرية للصف الأول الأسساسي، ويرد أحيانا باسهم الكتاب: وهو آخر كتاب لتعليم

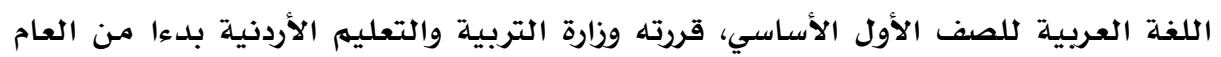

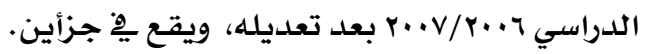

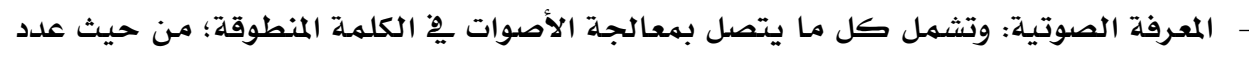
الأصوات وترتيبها وتمييزها وتقطيعها ومزجها من غير أن يكون لذلك علاقة بأنشطة فك

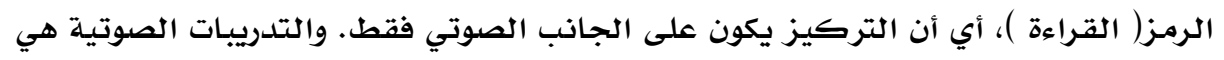
تلك المواقف المخططة يْ كتب القراءة للوصول بالطلبـة إلى المهارات والمعارف الصوتية الإزمـة. المبادئ التتظيمية: وتشير إلى الطريقة التي نظمت فيها التدريبات الصوتية فِ الكتاب وإلى العلاقات الداخلية التي تحكمها. الطريقة والإجراءات : استخدم الباحث المنهج الوصفي يخ تحليل كتاب اللغة العربية للصف الأول الأساسي بجزأيه. ومـن أجل ذلك أعد الباحث، بعد اطلاعه على الأدب التربوي يخ هذا المجال، استمارة خاصـة

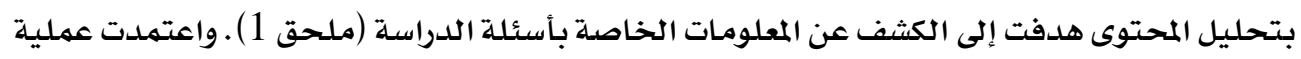
التحليل التدريبـات والصفحات التي تغطيها التدريبات على أنها وحدات للعد. واشتملت استمارة التحليل على أسماء الوحدات وعدد صفحاتها وعدد التدريبات الصوتية يِ كل منها ومساحة الصفحات التي غطتها التدريبات الصوتية، كما اشتملت الاستمارة على تصنيف التدريبات وفق المجالات المثار إليها يخ المقدمة، وقد شمل التحليل جميع وحدات الكتاب بجزأيه.

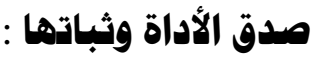

وللتأكد من صدق الأداة تم عرضها على مجموعة من المحكمـين مـن أساتذة الجـامعات والمشرفين التربويـين والمعلمـين المتميزين، وأجريت التعديلات اللازمـة يخ ضوء ذلك، ثم جرى التأكد من ثباتها مـن خلال إجـراء تحليل جزء مـن المحتوى وإعادة تحليله، وبعد تطبيق معادلة هولستي، بلغت نسبـة الاتفاق بين الإجـرائين 91\%، مها يشير إلى أن أداة الدراسـة تتمتع بنسبــة عالية مـن الثبات. 
اشتملت الدراسة على ثلاثة أسئلة ، وفيما يلى الإجابة على كل واحد منها كما كشفت

عن ذلك عملية التحليل:

السؤال الأول: ما مدى مراعاة كتاب الصف الأول الأساسي لمتطلبات التعليهم الصوتي من

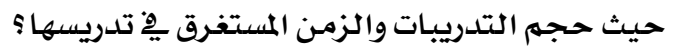

للإجابة عن هذا السؤال أحصى الباحث جميع التدريبات اللغوية ِيْ الكتاب، بما فيها

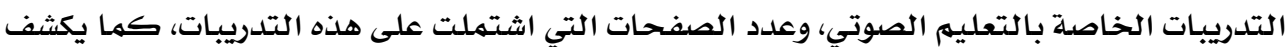

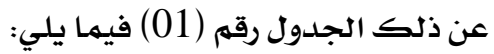

جدول (1)

يبين نسبة التدريبات الخاصة بالتعليم الصوتي إلى مجمل تدريبات الكتاب بجزأيه

\begin{tabular}{|c|c|c|c|c|c|c|}
\hline$\%$ & علدد صفحات & صفحات & $\%$ & علدد تلدريبات & عدد تدريبات & رقم الجزء \\
\hline$\cdot r, \Lambda$ & 4.02 & 144 & 06.9 & 22 & 318 & 01 \\
\hline 02.9 & 3.20 & 110 & 09.5 & 24 & 254 & 02 \\
\hline 02.9 & 7.22 & 254 & 08.0 & 46 & 572 & المجموع \\
\hline
\end{tabular}

يظهر الجدول السابق أن نسبة التدريبات الصوتية بلغت من حيث عددها 6.9 ٪ من مجموع الجماء

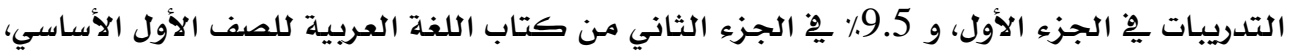

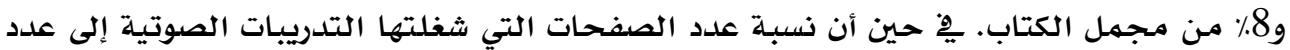

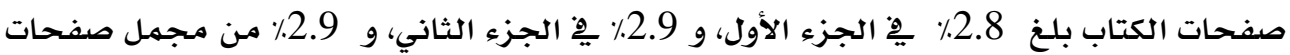

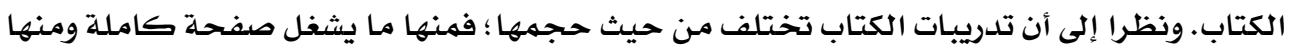

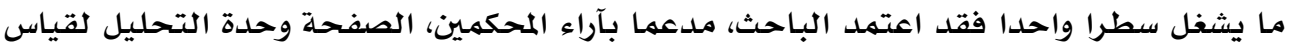

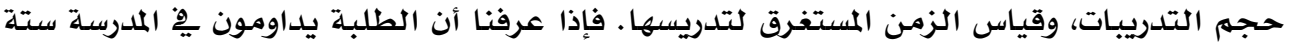

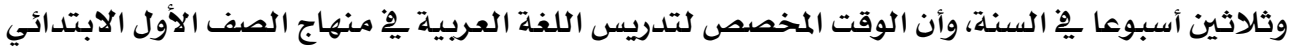

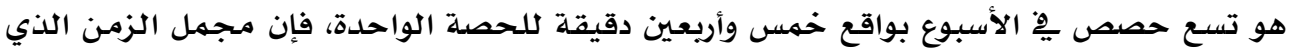

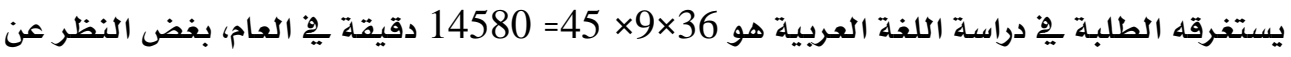

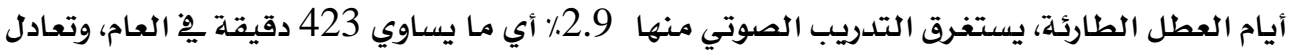

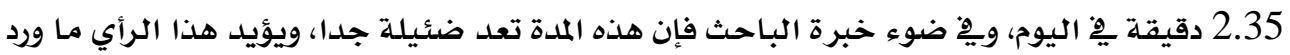

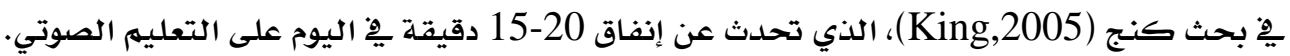

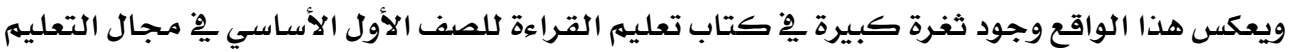

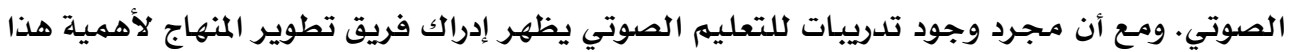

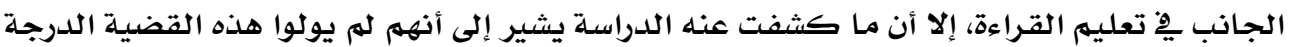




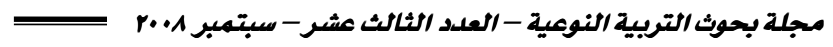

التي تستحقها من الاهتمام. ويفترض أن يزوَّد مؤلفو الكتب المدرسية بتعليمات واضحة تبين حجهم

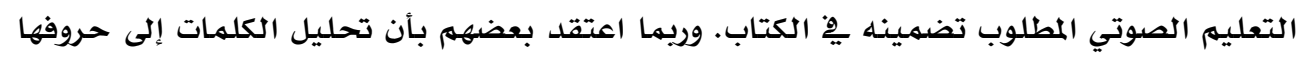

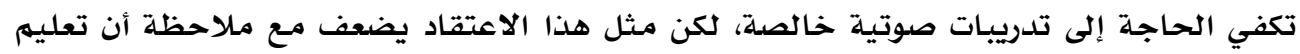

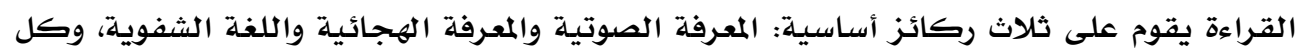

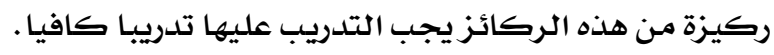

السؤال الثاني من أسئلة الدراسةة: ما مجالات التعليم الصوتي التي اشتملت عليها تدريبات

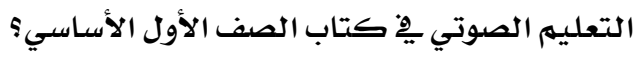

للإجابة عن هذا السؤال صنف الباحث تدريبات التعليهم الصوتي على النحو الذي يبينه

$$
\text { الجدول (2) الآتي : الاجمابة عن }
$$

\section{جدول (r)}

\begin{tabular}{|c|c|c|c|c|c|c|}
\hline$\%$ & المجموع & $\%$ & 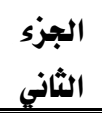 & $\%$ & 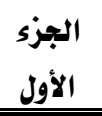 & 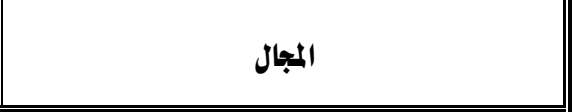 \\
\hline & 46 & & 24 & & 22 & مجموع التدريبات الصوتية \\
\hline & & & & & & | 1. التمييزبين الأصوات \\
\hline 00 & 00 & 00 & 00 & 00 & 00 & التمييز بين الأصوات المتقارية ف2 المخرج \\
\hline 00 & 00 & 00 & 00 & 00 & 00 & التمييز بين أصوات المد القصير والمد الطويل \\
\hline 12.3 & 05.66 & 18 & 04.33 & 06 & 01.33 & تمييز الصوت بِ أول الكلمة \\
\hline 10 & 04.66 & 18 & 04.33 & 01.5 & 0.33 & تمييز الصوت ف2 آخرالكلمة \\
\hline 75.5 & 34.66 & 64 & 15.33 & 88 & 19.33 & تمييز الصوت بِ وسط الكلمة \\
\hline 97.8 & 45 & 100 & 24 & 95.5 & 21 & مجموع تدريبات التمييز بين الأصوات \\
\hline 02.2 & 01 & 00 & 00 & 04.5 & 01 & 2. تحديد موقع الصوت يِ الكلمة من حيث ترتيبه \\
\hline 00 & 00 & 00 & 00 & 00 & 00 & 3. تحديد عدد الأصوات فِ الكلمة الواحدة. \\
\hline 00 & 00 & 00 & 00 & 00 & 00 & 4. تحديد الأصوات التي تختفي نتيجة الوصل بين \\
\hline 00 & 00 & 00 & 00 & 00 & 00 & |5. ملاحظة تغير المعنى بتغير الصوت. \\
\hline \multirow[t]{2}{*}{00} & 00 & 00 & 00 & 00 & 00 & 6. حذف أصوات من الكلمة أو إضافتها إليها \\
\hline & & & & & & 7. تقطيع الكلمات صوتيا \\
\hline 00 & 00 & 00 & 00 & 00 & 00 & تقطيع الكلمات صوتيا تقطيعا عروضيا \\
\hline 00 & 00 & 00 & 00 & 00 & 00 & تقطيع الكلمات صوتا صوتا \\
\hline 00 & 00 & 00 & 00 & 00 & 00 & |9. الذاكرة السمعية \\
\hline
\end{tabular}

يبين مجالات التعليم الصوتي يْ كتاب اللغة العربية للصف الأول الأساسي 


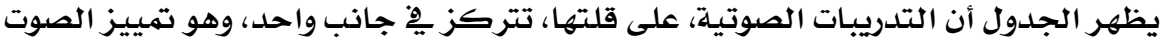

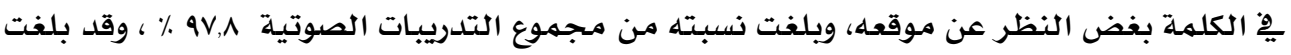

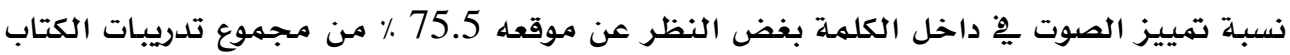

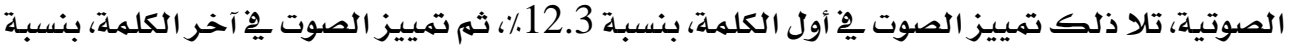

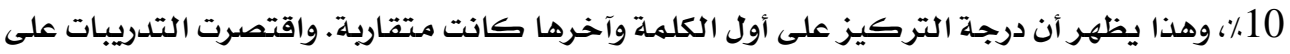

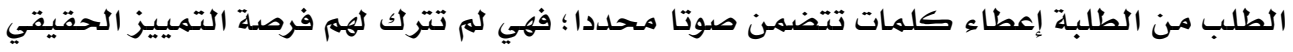

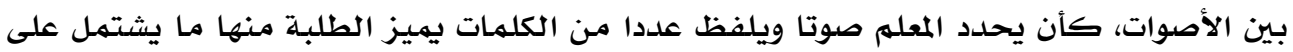

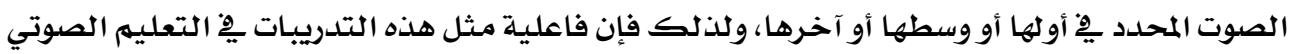

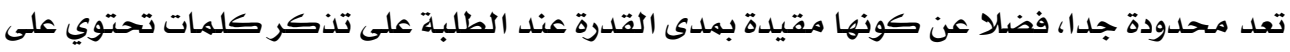

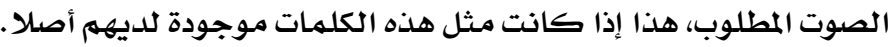
وقد خلا برنامـج التعليم الصوتي تماما من التدريب على كثير من المهارات مثل: تحديد

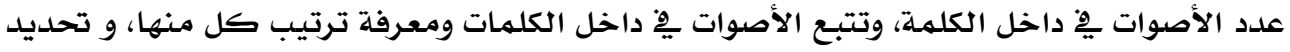

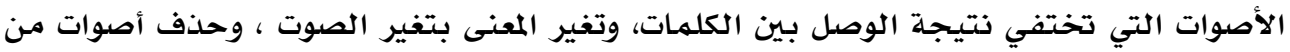

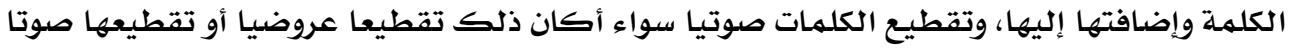

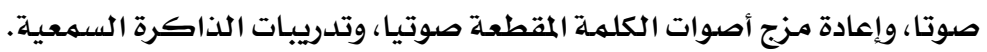

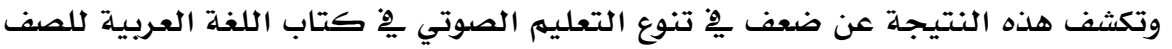

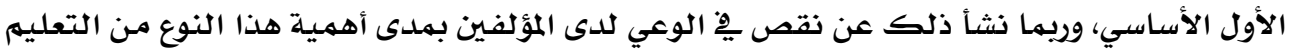

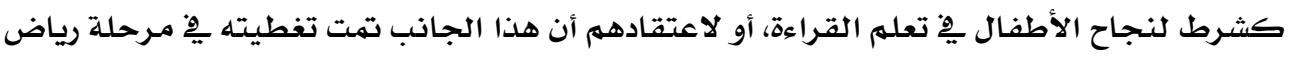

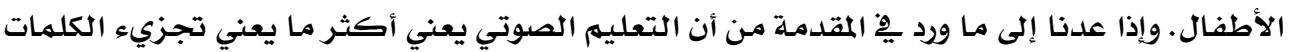

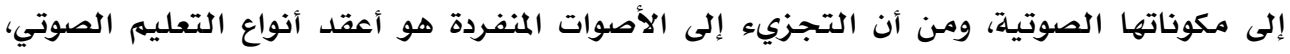

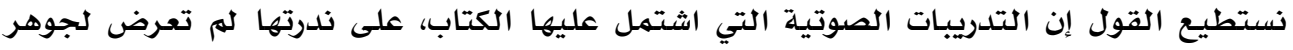

السؤال الثالث من أسئلة الدراسة: ما المبادئ التنظيمية الخاصدة يتدريبات التعليهم الصوتي

كما تكشف عنها عملية تحليل المحتوى؟

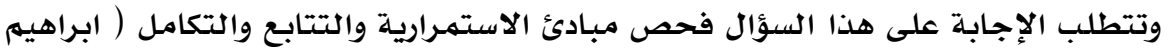

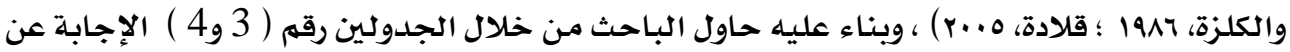
مجموعة الأسئلة الفرعية الآتية: والادة، 1- هل يوجد نظام واضح يِّ توزيع تدريبات التعليه الصوتي على دروس الكتاب بجزأيه، وبمعنى

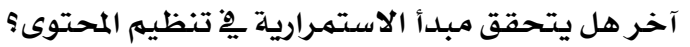

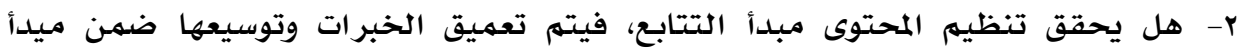
الاستمراريـة ؟ هل 


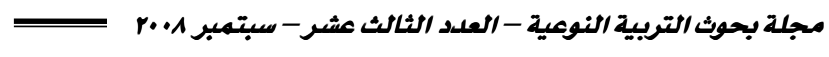

r- هل يوجد تكامل بين التدريبات الصوتية نفسها أو مـع غيرها من النشاطات المتصلة بتعليم

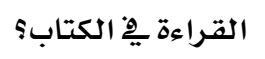

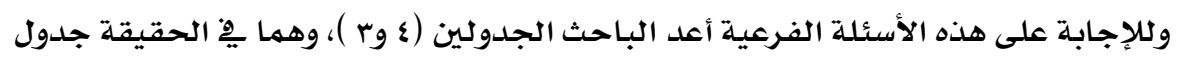

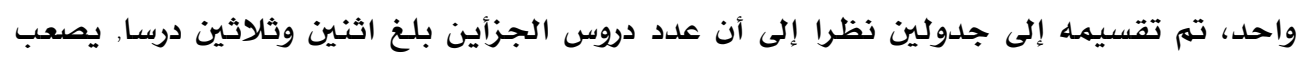

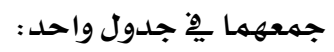

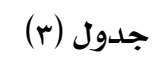

\begin{tabular}{|c|c|c|c|c|}
\hline التدريبات الصدوت صفحات & عدد التدريبـات & التدريبات & الصفحات & رقم الوحدة \\
\hline 00 & 00 & 20 & 16 & التهيئة \\
\hline 0.25 & 01 & 15 & 07 & 01 \\
\hline 0.25 & 01 & 16 & 07 & 02 \\
\hline .025 & 01 & 17 & 08 & 03 \\
\hline 0.40 & 02 & 19 & 08 & 04 \\
\hline 0.50 & $\mathbf{0 2}$ & 21 & 10 & 05 \\
\hline 0.50 & 03 & 20 & 08 & 06 \\
\hline 0.25 & 01 & 19 & 08 & 07 \\
\hline 0.25 & 01 & 21 & 08 & 08 \\
\hline 00 & 00 & 18 & 08 & 09 \\
\hline 0.2 & 01 & 20 & 08 & 10 \\
\hline 0.2 & 01 & 18 & 08 & 11 \\
\hline 0.2 & 02 & 17 & 08 & 12 \\
\hline 0.2 & 02 & 18 & 08 & 13 \\
\hline 0.1 & 01 & 21 & 08 & 14 \\
\hline 0.25 & 02 & 21 & 08 & 15 \\
\hline 0.2 & 01 & 17 & 08 & 16 \\
\hline 4.02 & 22 & 318 & 144 & المجموع \\
\hline
\end{tabular}

يبين توزيع التدريبات الخاصة بالتعليم الصوتي على دروس الكتاب/جا 
جدول (६)

يبين توزيع التدريبات الخاصة بالتعليم الصوتي على دروس الكتاب/جr

\begin{tabular}{|c|c|c|c|c|}
\hline عدد صفحات التدريبات & عدد التدريبات الصوتية & عدد التدريبات & عدد الصفحات & رقم الوحدة \\
\hline 00 & 00 & 12 & $\mathbf{0 8}$ & 17 \\
\hline 0.1 & 01 & 17 & 07 & 18 \\
\hline 0.1 & 01 & 16 & 07 & 19 \\
\hline 0.1 & 01 & 18 & 07 & 20 \\
\hline 0.1 & 01 & 15 & $\mathbf{0 7}$ & 21 \\
\hline 0.1 & 01 & 15 & $\mathbf{0 7}$ & 22 \\
\hline 0.1 & 01 & 15 & 07 & 23 \\
\hline 0.2 & $\mathbf{0 2}$ & 16 & 08 & 24 \\
\hline 0.3 & 01 & 16 & $\mathbf{0 8}$ & 25 \\
\hline $\mathbf{0 . 3}$ & 01 & 19 & 06 & 26 \\
\hline 0.4 & $\mathbf{0 3}$ & 18 & 07 & 27 \\
\hline 0.5 & $\mathbf{0 3}$ & 16 & 07 & 28 \\
\hline 0.1 & 01 & 16 & 07 & 29 \\
\hline 0.2 & $\mathbf{0 2}$ & 15 & 06 & 30 \\
\hline 0.5 & 04 & 16 & 05 & 31 \\
\hline 0.1 & 01 & 14 & 06 & 32 \\
\hline 3.2 & 24 & 254 & 110 & المجموع \\
\hline
\end{tabular}

بتأمل الجدولين (3) و(4) يتبين ما يلي:

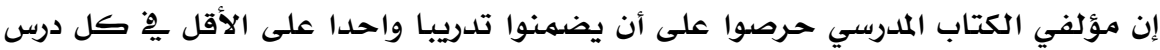

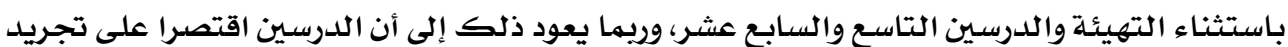
حركتي الفتحة وتنوين الكسر، ومع ذلك فإنه يهكن القول إن الكتاب راعى مبدأ الاستمرارية فيما

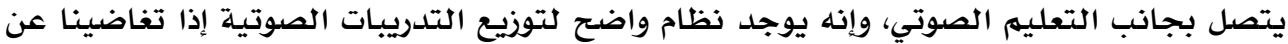
بعض الاستثناءات البسيطة. ويكشف الجدولان 4,3 أنه لا توجد خطة واضحة يِّ التوسع بِّ التدريبات داخل الكتاب؛ فقد

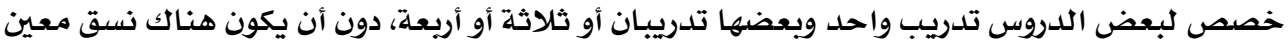

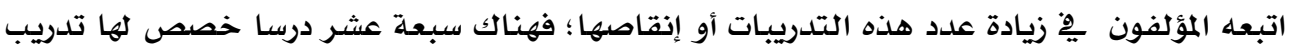

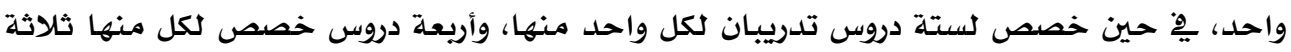


تدريبـات، ودرس واحد خصص لله أربعة تدريبـات، ودرسـان لهم يخصص لهما شيء.وقد تم ذلك كله بشكل عشوائي.

غير أنه لوحظ أن الدروس الثمانية الأولى اشتملت على صور تعين الطالب على استحضسار

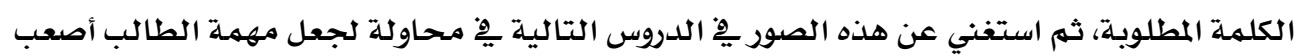

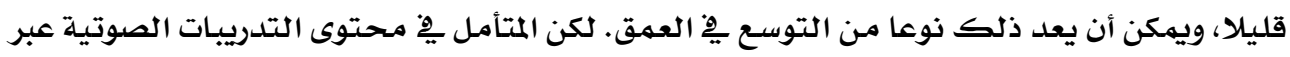
دروس الكتاب لا يتبـين درجة تذكر من الاختلاف ِِ مستواها، حتى تلك التي وردت تحت عنوان أفكر، فهي لهم تتجاوز يِ جوهرها سـائر التدريبات الأخرى التي تطلب من الطلبة إعطاء كلمات تشتهل على دوري حرف محدد. وفيما يتصل بالتكامل فقد لوحظ أن التدريبات الصوتية تم ربطها بالحروف التي يتم تجريدها يِّ الدروس المختلفة، وهذا يفسر خلو دروس التهيئة والدرسين التاسع والسـابع عشر من التدريبـات الصوتيهة، لأنه لهم يتتم فيها تجريد أي حرف من الحروف. كما يكثف بلدوره عن الفكرة التي تقف وراء عمليـة التدريب الصوتي لدى المؤلفين؛ فهم فيهما يبدو يعتقدون أن التعليهم الصوتي ليس إلا

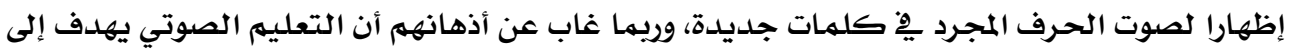
إكسـاب المتعلمـين معارف ومهارات صوتية، دون أن ترتبط بالضرورة بتعلىم الحروف أو الكلمات، وإن كانت تسهل مهمهة تعلمها . كها يتضـ أن التدريبـات لم تراع مبدأ التتوع؛ فجاءت يِ معظمها تدريبا على استدعاء كلمات تشتمل على صوت الحرف الذي تم تجريده،حيث بلغت نسبتها 97.8 ٪ كهما ذكر سـابقا وفقا لما كشف عنه جدول (2).وهذا يعني أن التدريبات الصوتية لا تشكل برنامجا

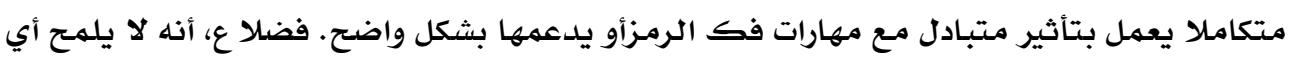
علاقة تذكر بين التدريب الصوتي وأغراض القراءة ومهاراتها . وهكذا يتبـين أن الكتاب اقتصر ِِ النعليهم الصوتي على نوع واحد من التدريبات فقط ، بالطلب من الأطفال تقديم كلمات تشتهل على صوت الحرف الذي تم تجريده يْ الدرس، وهذا

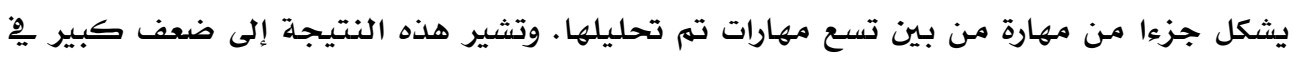
برنامـ التعليه الصوتي يٌْ كتاب الصف الأول الأسـاسي، وفيما يلي مجموعة من التوصيات:

ا - بناء بـرامـج خـاصدة بالتعليهم الصوتي تبدأ من رياض الأطفال وحتى الصف الثالث الأسـاسي. ب- زيادة وعي مصهمي المناهج والمشرفين التربويين ومؤلفي الكتب المدرسية، والمعلمـين في

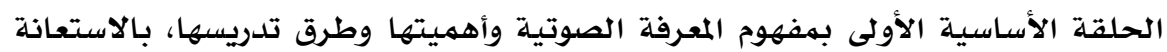

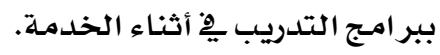

ب- إجراء مـزيد من الدراسـات التجريبيـية والوصفية يِ مجال المعرفة الصوتية. ع- الاستعانة بالحاسوب والبر امـج الصوتية المسجلة يِ التعليهم الصوتي كلأطفال. 


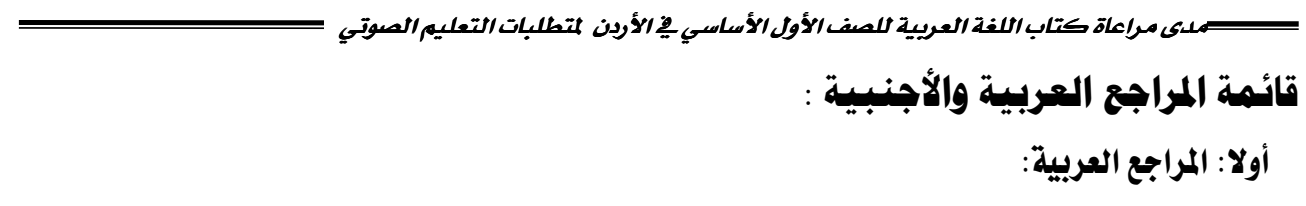

ا- إبراهيم، فوزي طه والكلزة، رجب أحمد (7191) . المناهج المعاصرة. مكة المكرمة: مكتبة الطالب الجامعي.

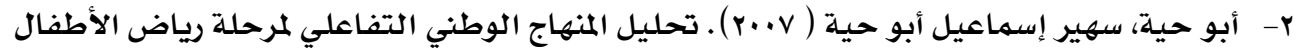

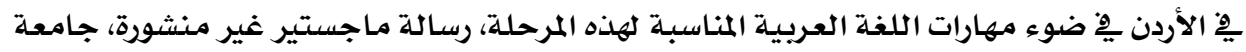
عمان العربية للدراسات العليا : عمان، الأردن.

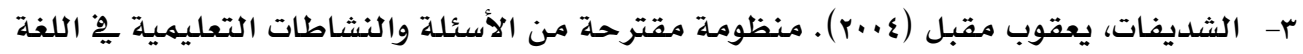

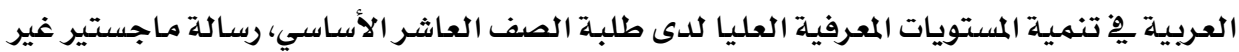
منشورة، جامعة عمان العربية للدراسات العليا : عمان، الأردان.

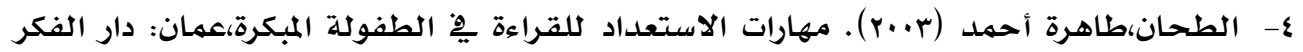
للطباعة والنشر والتوزيع.

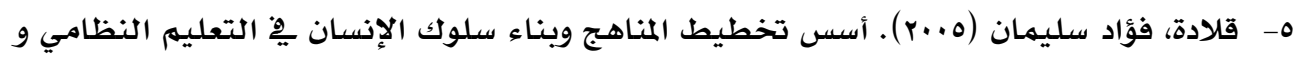

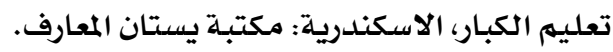

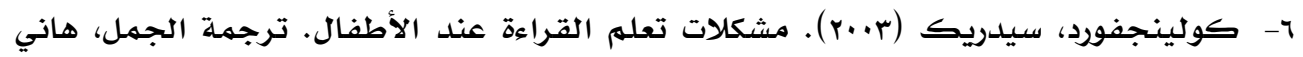

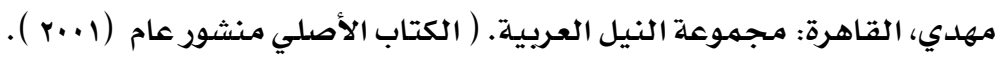

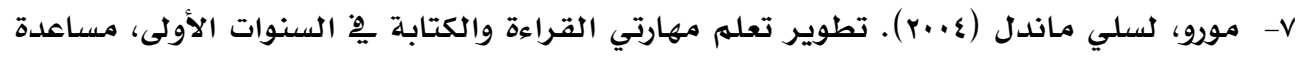

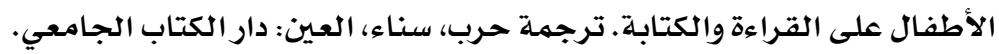

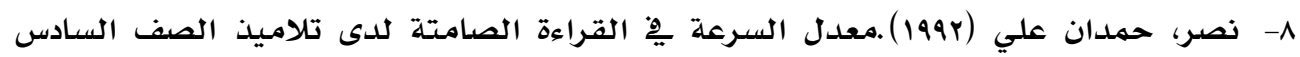

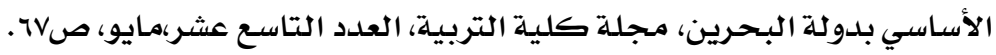

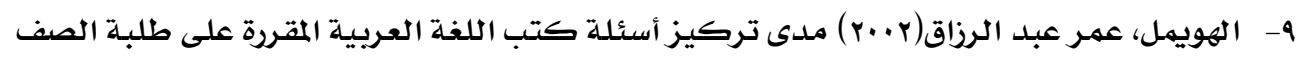

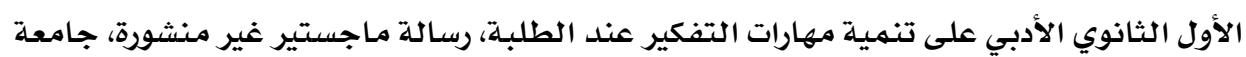
عمان العربية للدراسات العليا : عمان، الأردن. ثانيا: المراجع الأجنبية: انية

10. Bath,Preetha ; Griffen,Cynthia C. ; Sindelar,Paul T.(2003). Phonological Awareness Instruction for Middle School Students with learning Disabilities. Learning Disability Quarterly, V26, N2, 73-87.

11. Bradly,Barbara A. ; Jones,Jennifer(2007).Sharing Alphabet Book in early Childhood Classrooms. Reading Teacher, V60 N5, 452 - 463.

12. Dakin,Alexandra B. (1999).The Effectiveness of a Skilled Based Explicit Phonics Reading Program K-2 as Measured by Student Performance and Teacher Evaluation, Unpublished Master Thesis, Dominican College: Rafael, California. 
13.Ehri,LinneaKC.(2005).Learning to Read Words; Theory,Findings, and issues. Scientific Studies of Reading, V9,N2, 167-188.

14. Evans, Verlyn M. (2006). A Program to Improve Emergent Literacy Skills among African American Preschoolers. Online Submission, ED493954.

15. Foy,Judith G.(2006). Changes in Letter-Sound Knowledge Are Associated With Development of Phonological Awareness in Pre-School Children. Journal of Research in Reading, V29,N2, 143-161.

16. Hammil, Donald D.(2004). What we know about Correlates of Reading, Exceptional Children, V70,N4, 453.

17.Jongejan, Wilma ;Verhoeven, Ludo ; Siegel, Linda (2007). Predictors of Reading and Spelling Abilities in First - and Second- Languages Learners, Journal of Educational Psychology, V99, N4, 835-851.

18. King, Bernardine ;Wood,Clare; Faulkner,Dorothy (2007)> Journal Research in Reading,V30,N4, 443-453.

19. King,Melanic P. (2005). Direct Instruction in Phonological Awareness, Online Submission, ED490665.

20.Levin,Iris;Shatil - Carman,Sivan ;Asif - rave,Ornit (2006). Journal of Experimental Child Psychology, V93, N2, 139-165.

Neuman,Susan B.(2006).Early Literacy : Making Letter-Sound Correspondence. Early Childhood Today(3),V20,n6, 20-21.

22.Pullen,Paige C. ; Justice,Laura M.(2003). Enhancing Phonological Awareness, Print Awareness, and Preschool Children. Intervention in School and Clinic, V39, N2, 87- 98. 


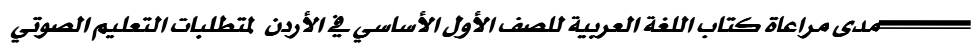
ملحق (1) استمارة تحليل المحتوى

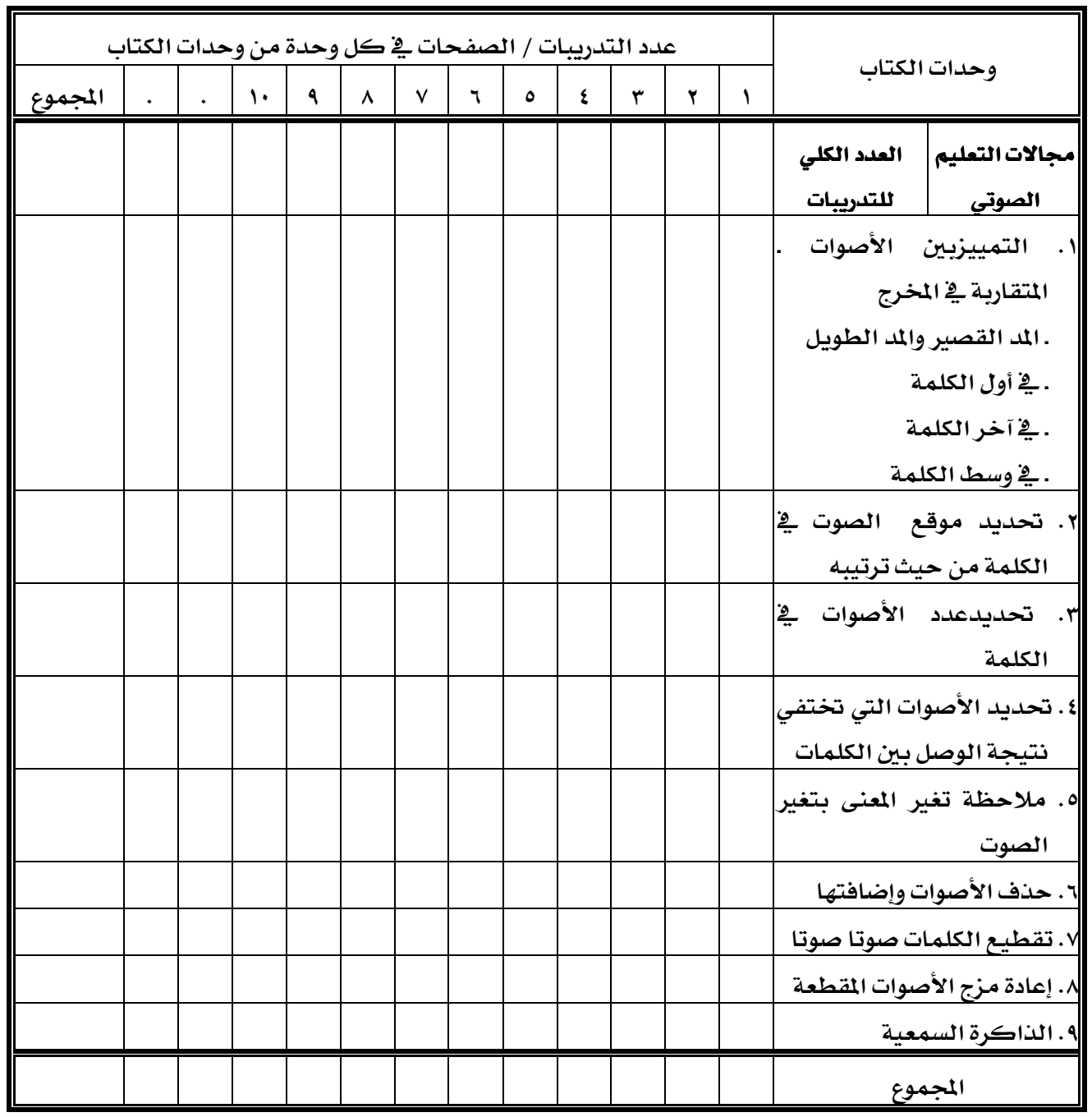

